\title{
EFEITO DA APLICAÇÃO DE RESÍDUOS URBANOS E INDUSTRIAIS NA CULTURA DA AVEIA PRETA CULTIVADA EM LATOSSOLO VERMELHO EM SISTEMA PLANTIO DIRETO
}

\author{
SUSIANE DE MOURA CARDOSO DOS SANTOS, JOÃO ARTHUR \\ ANTONANGELO, ANGÉLICA CRISTINA FERNANDES DEUS, LEONARDO \\ THEODORO BÜLL
}

\footnotetext{
${ }^{1}$ Universidade Estadual de Mato Grosso do Sul, Cassilândia/MS, Brasil, susianemoura@ yahoo.com.br, ${ }^{2}$ Universidade de São Paulo, Escola Superior de Agricultura "Luiz de Queiroz”, Piracicaba/SP, Brasil, joaoantonangelo@ usp.br, ${ }^{3}$ Universidade Estadual Paulista "Júlio de Mesquita Filho", Faculdade de Ciências Agronômicas, Botucatu/SP, Brasil, angelica_agronomia@yahoo.com.br, bull@fca.unesp.br
}

RESUMO: O emprego racional de resíduos industriais e urbanos na agricultura sob sistema plantio direto (SPD) promove inúmeros benefícios sobre as propriedades físicas, químicas e biológicas do solo, reduzindo assim, a utilização de fertilizantes sintéticos, proporcionando efeitos benéficos ao solo e ao ecossistema. Além de atuarem como atenuadores da acidez do solo, esses resíduos são excelentes fontes de nutrientes às plantas. $\mathrm{O}$ trabalho teve como objetivo avaliar o estado nutricional e a produção de matéria seca da aveia preta após aplicação de resíduos industriais e urbanos sob sistema plantio direto. Trata-se de um trabalho em longo prazo, perfazendo um período de nove anos, onde até o presente momento ocorreram cinco aplicações de resíduos em 2002, 2005, 2007, 2009 e 2011. O delineamento experimental utilizado foi o de blocos casualizados, com quatro repetições. Os tratamentos foram compostos por quatro resíduos, sendo dois urbanos (lodo centrifugado e de biodigestor) e dois industriais (escória de aciaria e lama cal). Foi determinado a massa de matéria seca e os teores de macro e micronutrientes da aveia preta. A dose de $8 \mathrm{Mg} \mathrm{ha}^{-1}$ foi a única que apresentou diferença significativa para a produção de matéria seca dentre os resíduos aplicados. Os macros nutrientes $\mathrm{N}, \mathrm{P}, \mathrm{K}$ e $\mathrm{S}$ não apresentaram diferença em função das doses. A aplicação dos resíduos nas diferentes doses não influenciou os teores de $\mathrm{Cu}$ e $\mathrm{Fe}$.

PALAVRAS-CHAVE: Avena strigosa, lodo de esgoto, escória de aciaria, lama cal, massa de matéria-seca.

\section{EFFECTS OF APPLICATION OF INDUSTRIAL AND MUNICIPAL WASTE IN THE BLACK OAT CROP IN AN OXISOL UNDER NO-TILL}

\begin{abstract}
The rational use of industrial and municipal waste in agriculture under no-till (NT) may promote benefits on the physical, chemical and biological properties of soil, thus reducing the use of synthetic fertilizers, providing beneficial effects to soil and ecosystem. In addition to reducing the acidity of the soil, these residues are excellent sources of nutrients for plants. The objective of this was to evaluate the nutritional status and dry matter yield of black oats after application of industrial and municipal waste under no-till. This is a long-term experiment, for a period of nine years, where five waste applications were performed: 2002, 2005, 2007, 2009 and 2011. The experimental design was a randomized block with four replications. The treatments consisted of four residues, two municipal wastes (sludge centrifuged and biodigester sludge) and two industrial wastes (blast furnace slag and lime slurry). The dry matter yield and nutrient contents of black oats were determined. The rate of
\end{abstract}


$8 \mathrm{Mg} \mathrm{ha}^{-1}$ was the only one that showed a significant difference for the dry matter yield from industrial and municipal waste applied. The concentrations of $\mathrm{N}, \mathrm{P}, \mathrm{K}$ and $\mathrm{S}$ have not shown any difference as affected of the waste rates. The waste application rates did not affect the levels of $\mathrm{Cu}$ and $\mathrm{Fe}$.

KEY WORDS: Avena strigosa, sewage sludge, blast furnace slag, lime slurry, dry matter yield.

\section{INTRODUÇÃO}

A reciclagem agrícola de resíduos urbanos domiciliares e industriais tornou-se uma alternativa racional e promissora para preservar o meio ambiente e, ao mesmo tempo, é uma solução ao problema criado pelo aumento de tais rejeitos, isso por se tratar de um composto rico em matéria orgânica e nutrientes para as plantas, principalmente fósforo e nitrogênio (ROS et al., 1993), promovendo melhorias nos atributos químicos do solo. O uso de lodos de esgoto, lama cal e escória de aciaria na agricultura contribuem para reduzir o consumo de fertilizantes inorgânicos, devido à presença de nutrientes essenciais às plantas e matéria orgânica e em alguns casos reduzir a neutralização da acidez do solo, denotando assim uma redução de custos pela agricultura e diminuição do acúmulo nos centros de produção (GALDO et al., 2004; CARVALHO-PUPATTO et al., 2004).

A utilização de lodos de esgoto do tipo centrifugado e de biodigestor na agricultura, além de eliminar um resíduo socialmente incomodo, permite o aproveitamento dos elementos nutritivos e compostos orgânicos nele contidos pelas plantas. (MELFI et al., 2001; TSUTIYA et al., 2001; CORRÊA, 2001; OLIVEIRA et al., 2002; NASCIMENTO et al., 2004). O seu uso na correção da acidez do solo, elevando o valor de $\mathrm{pH}$ e neutralizando o Al tóxico foi constatado em vários trabalhos conduzidos por Bataglia et al. (1983), Berton et al. (1989), Oliveira, (1996), Berton et al. (1997), Melo e Marques (2001), Corrêa et al., (2009) e Tsutiya et al. (2001).

O resíduo industrial escória de aciaria, proveniente de siderúrgicas, apresenta comportamento semelhante ao calcário, sendo justificado seu uso como corretivo de acidez, de acordo com Piau, (1991); Pereira, (1978); Veloso et al. (1992); Louzada, (1987). Além do mais, Corrêa et al. (2008), afirmam que a maior produtividade da aveia preta é decorrente da aplicação dos resíduos lodo centrifugado (LC), lama cal (Lcal) e escória (E), uma vez que, apresentam em sua composição constituintes de neutralização da acidez do solo.

Entretanto, estudos realizados demonstram que tal sistema promove mudanças nos atributos, físicos, químicos e biológicos do solo, melhorando sua fertilidade, em relação ao sistema convencional. Quimicamente, a aplicação de resíduos urbanos ao solo tem propiciado elevação dos teores de vários elementos, dentre eles o de fósforo, carbono orgânico da fração húmica da matéria orgânica, do $\mathrm{pH}$, da condutividade elétrica e da capacidade de troca de cátions (OLIVEIRA et al., 2002).

No que diz respeito ao SPD, Amado et al. (2003) afirma que a adoção do sistema plantio direto com o uso da aveia preta, antecedendo o cultivo de soja e milho no verão na região Sul do Brasil, tem-se mostrado como eficiente estratégia de manejo do solo, além de ser uma eficiente planta de cobertura e importante fonte para ciclagem dos nutrientes, uma vez que, prova ser grande recicladora de $\mathrm{Ca}, \mathrm{Mg}$ e $\mathrm{Mn}$ (BORKERT et al., 2003). Em decorrência desses fatores, uma eficiente estratégia para aumentar a eficiência da planta de aveia como planta de cobertura, seria a utilização de resíduos com altos teores de nitrogênio, sendo assim, aumentando a produção de fitomassa e consequentemente maior reciclagem de nutriente em SPD (AMADO et al., 2003). 
Unindo os benefícios do Sistema Plantio Direto e a aplicação de lodos de esgoto e resíduos industriais, objetivou-se analisar as alterações químicas na planta de aveia preta, bem como a produção de matéria seca, após a aplicação dos resíduos em Sistema de Plantio Direto.

\section{MATERIAL E MÉTODOS}

O trabalho foi conduzido durante o ano agrícola de 2011/2012, na Fazenda Experimental Lageado, pertencente à Faculdade de Ciências Agronômicas - FCA, Campus de Botucatu/UNESP, localizada no município de Botucatu-SP, na latitude de $22^{\circ} 51^{\prime}$ S, longitude de $48^{\circ} 26^{\prime} \mathrm{W}$ e altitude de $740 \mathrm{~m}$. O experimento foi conduzido em área, a qual vem sendo manejada em sistema plantio direto, e com a aplicação de resíduos urbanos (lodo de esgoto) e industriais (escória de aciaria e lama cal) em superfície desde o ano de 2002. Segundo a classificação climática de Köeppen, o clima predominante na região é do tipo Cwa, caracterizado pelo clima tropical de altitude, com inverno seco e verão quente e chuvoso. $\mathrm{O}$ solo da área experimental é classificado como Latossolo Vermelho distrófico (EMBRAPA, 1999).

O delineamento experimental utilizado foi o de blocos casualizados, com quatro repetições. As parcelas foram de 5,7 $\mathrm{m}$ de largura e 7,0 $\mathrm{m}$ de comprimento. Os tratamentos foram constituídos por quatro tipos de resíduos, dois tipos de resíduos urbanos, um centrifugado, proveniente da estação de tratamento de esgoto de Presidente Prudente e um de biodigestor, produzido pela estação de tratamento de esgoto de Barueri, e dois resíduos industriais, a escória de aciaria obtida pela Empresa Mannesmann e a lama cal proveniente da empresa de celulose Ripasa. As caracterizações químicas destes resíduos estão descritas na Tabela 1. Vale ressaltar que Corrêa et al. (2008), utilizando os mesmos resíduos industriais e urbanos não observaram alteração nos teores de metais pesados em Latossolo Vermelho distrófico sob sistema plantio direto.

Tabela 1. Composição química dos resíduos: Lodo de esgoto centrifugado tratado com cal virgem (LC) e Lodo de esgoto de biodigestor (LB), Lama cal (Lcal) e Escória de aciaria (E). Botucatu, 2012.

\begin{tabular}{ccccccccccccccccc}
\hline \multirow{2}{*}{ Resíduo } & $\mathrm{C} / \mathrm{N}$ & $\begin{array}{c}\mathrm{pH} \\
\mathrm{CaCl}_{2}\end{array}$ & Umidade & M.O. & $\mathrm{N}$ & $\mathrm{P}_{2} \mathrm{O}_{5}$ & $\mathrm{~K}_{2} \mathrm{O}$ & $\mathrm{Ca}$ & $\mathrm{Mg}$ & $\mathrm{S}$ & $\mathrm{Na}$ & $\mathrm{Cu}$ & $\mathrm{Fe}$ & $\mathrm{Mn}$ & $\mathrm{Zn}$ \\
\hline $\mathrm{LC}$ & $7 / 1$ & 8,1 & 25 & $10, \ldots$ & 0,8 & 0,4 & 0,1 & 12,1 & 0,2 & 0,1 & 270 & 75 & 4388 & 69 & 180 \\
$\mathrm{LB}$ & $8 / 1$ & 6,8 & 18,9 & 42,1 & 3 & 3,4 & 0,1 & 1,9 & 0,4 & 0,7 & 243 & 99 & 17334 & 322 & 1176 \\
$\mathrm{Lcal}$ & $93 / 1$ & 8,8 & 37,3 & 10,1 & 0,1 & 0,2 & 0,6 & 16,8 & 0,2 & 0 & 3263 & 6 & 265 & 91 & 9 \\
$\mathrm{E}$ & $11 / 1$ & 12,4 & 10,0 & 2 & 0,1 & 1,2 & 0 & 21,8 & 2,4 & 0,9 & 684 & 23 & 145350 & 22455 & 25 \\
\hline
\end{tabular}

No dia 25 de agosto de 2011, foi realizada a aplicação dos resíduos urbanos (lodo centrifugado e de biodigestor) e os resíduos industriais (escória de aciaria e lama cal). Todos os resíduos foram aplicados de forma superficial e homogênea, seguindo as doses de 0, 2, 4 e $8 \mathrm{Mg} \mathrm{ha}^{-1}$ e distribuídas em blocos ao acaso. Os resíduos e as doses utilizadas no experimento foram pré-estabelecidos com base em um ensaio preliminar com duração de um mês, mediante incubação em casa de vegetação de várias doses de cada um dos resíduos em sacos plásticos contendo $1 \mathrm{~kg}$ de terra proveniente da área experimental, com teor de umidade de $70 \%$ da capacidade de campo, para determinar o poder de neutralização dos resíduos das escórias, afim de não ultrapassar o valor de pH 7,0 em $\mathrm{CaCl}_{2}$ (TSUTIYA et al., 2001; MELO et al., 2001), para só então, definir as doses que seriam aplicadas inicialmente. 
Os micronutrientes foram analisados através da extração com DTPA-TEA, método descrito por Camargo et al. (1986) e o boro determinado através do método de cloreto de bário-microondas, método descrito por Abreu et al. (1998).

Anteriormente à implantação da cultura da aveia preta (cobertura de inverno), a vegetação espontânea foi dessecada com a aplicação de $1,920 \mathrm{~g}$ i.a. ha ${ }^{-1}$ de herbicida a base de glyphosate. Após o final do ciclo da cultura da aveia (ano agrícola 2011/2012), foi coletado material para avaliações, sendo esta dessecada. Para a determinação da massa de matéria seca da parte aérea foram coletadas as plantas presentes em uma área de $0,25 \mathrm{~m}^{2}$, com o auxílio de uma estrutura vazada confeccionada em madeira, contendo dimensões de $0,50 \times 0,50 \mathrm{~m}$. $\mathrm{O}$ material vegetal foi seco em estufa de circulação de ar forçado à temperatura de $60^{\circ} \mathrm{C}$ por 48 horas. Parte desse material seco foi moído e encaminhado para análise química dos teores de macro e micronutrientes, conforme metodologia descrita por Malavolta et al. (1997).

Os resultados foram submetidos à análise de variância através de regressão, adaptando a melhor equação, através da aplicação do teste $\mathrm{F}$ a $1 \%$ e $5 \%$, e do teste de médias entre os tratamentos, com a aplicação do teste de Tukey a $1 \%$ e $5 \%$, através do programa Sisvar, versão 4.2 .

\section{RESULTADOS E DISCUSSÃO}

A produção de massa de matéria seca da aveia apresentou diferença significativa entre os resíduos na dose de $8 \mathrm{Mg} \mathrm{ha}^{-1}$ resultados esse confirmados por Corrêa et al. (2009), cultivando aveia preta nas mesmas condições (Tabela 2). Tais diferenças mostram-se bastante relevantes, uma vez que os resíduos LB e Lcal proporcionaram os menores valores médios, enquanto que o LC apresentou o maior valor de massa de matéria seca para a cultura da aveia. No entanto, não houve diferença significativa para as doses de $2 \mathrm{Mg} \mathrm{ha}^{-1} \mathrm{e} 4 \mathrm{Mg} \mathrm{ha}^{-1}$ aplicadas, nos quatro tipos de tratamento.

Na Tabela 2, nota-se que os maiores valores encontrados são provenientes da aplicação de escoria, demonstrando sua eficiência como fonte de nutrientes à planta.

Tabela 2. Produção de massa de matéria seca na cultura da aveia, em função da aplicação superficial dosresíduos LB (lodo de biodigestor), LC (lodo centrifugado com adição de cal), Lcal (lama cal), E (escória de aciaria), sob Sistema Semeadura Direta na safra 11. Botucatu, SP.

\begin{tabular}{ccccc}
\hline Dose & LB & LC & Lcal & E \\
\cline { 2 - 5 } Mg ha $^{-1}$ & \multicolumn{5}{c}{........ Matéria seca kg ha ${ }^{-1} \ldots \ldots \ldots .}$. \\
\hline 0 & 1178,4 & 1178,4 & 1178,4 & 1178,4 \\
2 & 2128,5 & 2274,7 & 2244,2 & 2259,7 \\
4 & 2363,3 & 2168,3 & 1845,3 & 2589,3 \\
8 & $1691,3 \mathrm{~b}$ & 3217,1 & $1459,9 \mathrm{~b}$ & $2938,4 \mathrm{a}$ \\
\hline Média & 1840,4 & 2209,6 & 1682 & 2241,5 \\
\hline $\mathrm{CV}(\%)$ & \multicolumn{4}{c}{24,44} \\
\hline
\end{tabular}

A aplicação superficial de resíduos no solo, no ano de 2011, foi de fundamental importância, para maior produtividade de biomassa da aveia preta, em função do aumento das doses dos resíduos (Figura 1), sendo que todos os resíduos ajustaram-se a curvas quadráticas crescentes até a última dose utilizada, com exceção ao resíduo LB, que demonstra decréscimo na dose $8 \mathrm{Mg} \mathrm{ha}^{-1}$, o que pode estar relacionado ao alto teor de $\mathrm{Zn}$ presente na composição 
desse resíduo (Tabela 1). Foram alcançados incrementos de até 2038 e $1760 \mathrm{~kg} \mathrm{ha}^{-1}$ nos tratamentos de LC e E na dose de $8 \mathrm{t} \mathrm{ha}^{-1}$, em relação à testemunha. Esse aumento representa grande contribuição na disponibilidade e reciclagem de nutrientes, para a cultura subsequente.

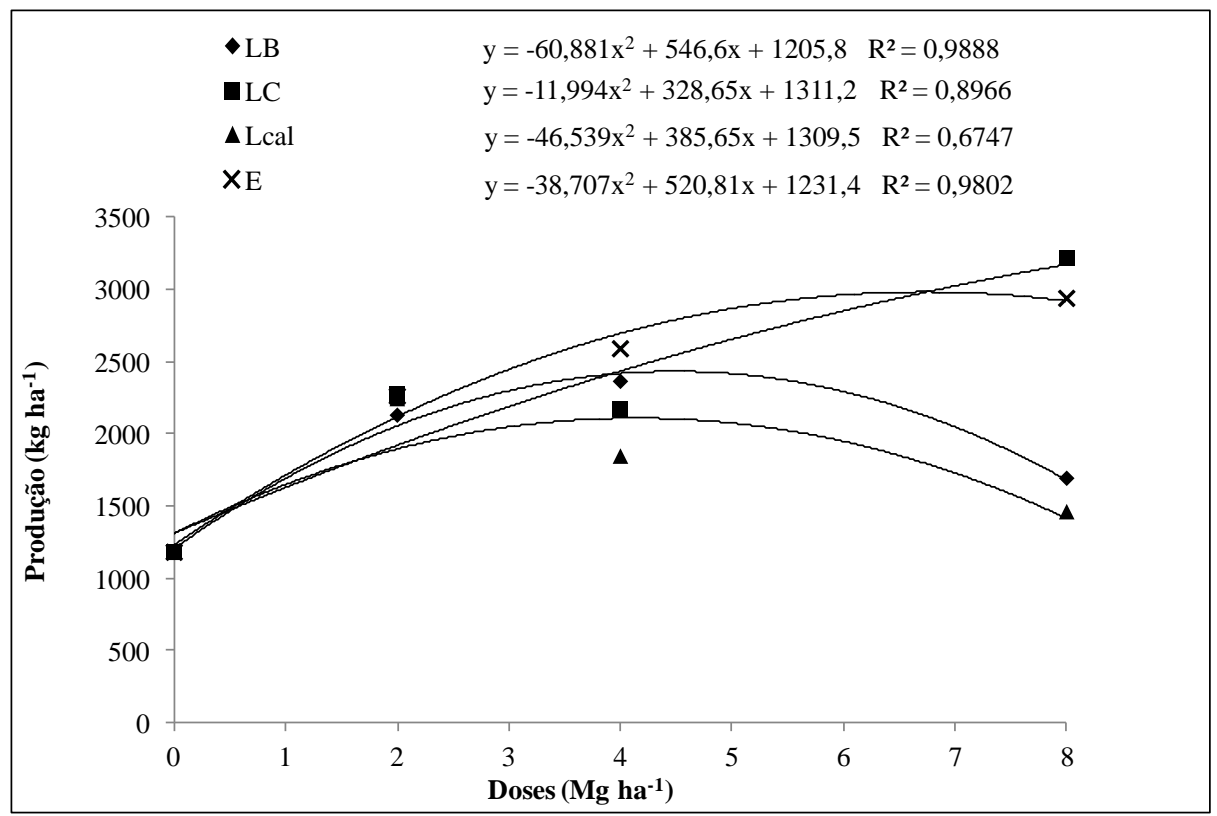

Figura 1. Produção da cultura da aveia, três meses após a última aplicação dos resíduos LB, LC, Lcal e E em Sistema Semeadura Direta.

Segundo a diagnose foliar da aveia preta, nota-se que os nutrientes $N, P, K$ e S não apresentaram diferenças significativas nas diferentes doses, sendo que $\mathrm{N}$ e $\mathrm{P}$ estão abaixo da faixa considerada adequada para a cultura da aveia (Tabela 3). Além do mais, o teor de P, entre os macronutrientes, é o nutriente reciclado em menor quantidade pela aveia preta, variando de 8 a $12 \mathrm{~kg} \mathrm{ha}^{-1}$, no intervalo de 5 a $10 \mathrm{Mg} \mathrm{ha}^{-1}$ de matéria seca (BORKET et al., 2003).

Segundo Raij et al. (1997), a faixa de teores adequados para N, P e K nas folhas da cultura da aveia são de 20 - 30 de $2,0-5,0$ e de $15-30 \mathrm{~g} \mathrm{~kg}^{-1}$, respectivamente. No caso do K e S, estes estão dentro da faixa aceitável para a nutrição da planta (RAIJ et al. 1997).A aplicação do resíduo LB na dose de $8 \mathrm{Mg} \mathrm{ha}^{-1}$ foi responsável pelo maior valor de $\mathrm{N}(12,19 \mathrm{~g}$ $\mathrm{kg}^{-1}$ ), o que pode ser explicado pelo fato desse resíduo conter porcentagem de $\mathrm{N}$ maior que os outros resíduos utilizados (Tabela 1).

Os maiores teores de $\mathrm{K}$ na planta (Tabela 3) foram observados com o tratamento testemunha e com a aplicação do resíduo LB, o que também corrobora com os dados Corrêa (2009), proporcionando maiores teores na parte aérea da aveia preta. Para o Ca, os valores estão dentro do aceitável, e os maiores valores encontrados foram com as aplicações dos resíduos LC e Lcal na dose de $4 \mathrm{Mg} \mathrm{ha}^{-1}$, e o menor teor encontrado foi da dose testemunha, seguida do resíduo LB na dose $8 \mathrm{Mg} \mathrm{ha}^{-1}$, efeito esse justificado pela quantidade reduzida de Ca em sua composição (Tabela 1).

Quanto ao $\mathrm{Mg}$, os maiores teores foram observados com aplicação de E (Tabela 3). Resultados justificados pelo fato do resíduo $\mathrm{E}$ apresentar quantidade considerável desse nutriente em sua composição (Tabela 1), no entanto, apenas a dose de $8 \mathrm{Mg} \mathrm{ha}^{-1}$ apresentou diferença significativa quanto ao teor desse nutriente em comparação as demais doses aplicadas. 
Tabela 3. Teores foliares de micronutrientes na cultura da aveia, decorrente da aplicação superficial dos resíduos LB (lodo de biodigestor), LC (lodo centrifugado com adição de cal), Lcal (lama cal), E (escória de aciaria), sob Sistema Semeadura Direta na safra 11/11. Botucatu, SP.

\begin{tabular}{|c|c|c|c|c|c|c|c|c|}
\hline \multicolumn{9}{|c|}{ Resíduos } \\
\hline Dose & LB & $\mathrm{LC}$ & Lcal & $\mathrm{E}$ & LB & $\mathrm{LC}$ & Lcal & $\mathrm{E}$ \\
\hline $\mathrm{Mg} \mathrm{ha}^{-1}$ & \multicolumn{4}{|c|}{..... $\mathrm{N}\left(\mathrm{g} \mathrm{Kg}^{-1}\right)}$. & \multicolumn{4}{|c|}{$\ldots . . P\left(\mathrm{~g} \mathrm{Kg}^{-1}\right) \ldots$} \\
\hline 0 & 6,7 & 6,7 & 6,7 & 6,7 & 0,6 & 0,6 & 0,6 & 0,6 \\
\hline 2 & 6,6 & 8,4 & 8 & 8,2 & 0,4 & 0,3 & 0,5 & 0,6 \\
\hline 4 & 6,4 & 10,4 & 8,6 & 5,9 & 0,4 & 0,7 & 0,6 & 0,5 \\
\hline 8 & 12,2 & 6,6 & 10,5 & 7,4 & 0,8 & 0,4 & 0,8 & 0,6 \\
\hline Média & 8 & 8,2 & 8,5 & 7,1 & 0,5 & 0,5 & 0,6 & 0,6 \\
\hline Regressão & $\mathrm{ns}$ & ns & ns & $\mathrm{ns}$ & $\mathrm{ns}$ & ns & ns & $\mathrm{ns}$ \\
\hline Dose & LB & $\mathrm{LC}$ & Lcal & $\mathrm{E}$ & LB & $\mathrm{LC}$ & Lcal & $\mathrm{E}$ \\
\hline $\mathrm{Mg} \mathrm{ha}^{-1}$ & \multicolumn{4}{|c|}{$\ldots \ldots \mathrm{K}\left(\mathrm{g} \mathrm{Kg}^{-1}\right) \ldots \ldots \ldots \ldots \ldots \ldots$} & \multicolumn{4}{|c|}{.... Ca $\left(\mathrm{g} \mathrm{Kg}^{-1}\right)$. } \\
\hline 0 & 20,5 & 20,5 & 20,5 & 20,5 & 2,8 & 2,8 & 2,8 & 2,8 \\
\hline 2 & 22,7 & 15,9 & 16,9 & 16 & 3,4 & 4,2 & 4,7 & 3,5 \\
\hline 4 & 19,5 & 14,8 & 14,4 & 19 & $3,5 b$ & $5,2 \mathrm{ab}$ & $5,8 \mathrm{a}$ & $4,6 \mathrm{ab}$ \\
\hline 8 & 19,8 & 20,4 & 15,6 & 13,9 & $2,7 \mathrm{~b}$ & $5 \mathrm{a}$ & $4,6 a b$ & $4,9 \mathrm{ab}$ \\
\hline Média & 20,6 & 17,4 & 16,4 & 16,9 & $3,1 b$ & $4,5 \mathrm{a}$ & $4,7 \mathrm{a}$ & $4,1 \mathrm{ab}$ \\
\hline Regressão & $\mathrm{ns}$ & ns & $\mathrm{ns}$ & ns & $\mathrm{Q}^{*}$ & $\mathrm{Q}^{*}$ & $\mathrm{Q}^{*}$ & $\mathrm{Q}^{*}$ \\
\hline Dose & LB & $\mathrm{LC}$ & Lcal & $\mathrm{E}$ & LB & $\mathrm{LC}$ & Lcal & $\mathrm{E}$ \\
\hline $\mathrm{Mg} \mathrm{ha}^{-1}$ & \multicolumn{4}{|c|}{$\ldots \mathrm{Mg}\left(\mathrm{g} \mathrm{Kg}^{-1}\right) \ldots$} & \multicolumn{4}{|c|}{$\ldots . \mathrm{S}\left(\mathrm{g} \mathrm{Kg}^{-1}\right) \ldots$} \\
\hline 0 & 0,9 & 0,9 & 0,9 & 0,9 & 1,9 & 1,9 & 1,9 & 1,9 \\
\hline 2 & 0,9 & 0,9 & 1,1 & 1,4 & 2 & 1,8 & 2 & 2,1 \\
\hline 4 & 1,1 & 1,2 & 0,9 & 1,1 & 2 & 2 & 2,2 & 2,1 \\
\hline 8 & $1 \mathrm{ab}$ & $0,8 \mathrm{ab}$ & $1,2 \mathrm{ab}$ & $1,4 \mathrm{ab}$ & 2,1 & 1,9 & 2,2 & 2,1 \\
\hline Média & 1 & 1 & 1 & 1,3 & 2 & 1,9 & 2,1 & 2,1 \\
\hline Regressão & ns & ns & ns & ns & $\mathrm{ns}$ & ns & ns & ns \\
\hline
\end{tabular}

Com relação aos micronutrientes, o $\mathrm{Cu}$ e $\mathrm{Fe}$ não demonstraram diferenças significativas em nenhum dos quatro resíduos, nem nas diferentes doses aplicadas, porém, apenas o Fe está dentro da faixa aceitável para a nutrição da planta $\left(5-25,40-150 \mathrm{mg} \mathrm{kg}^{-1}\right.$, respectivamente) (Raij et al. 1997). Os B, Mn e Zn apresentaram diferença significativa em relação às diferentes doses de resíduos aplicadas, porém o Zn manteve-se abaixo do ideal para a cultura, com exceção às maiores doses dos resíduos LB e Lcal aplicadas. As médias dos teores encontrados nas folhas de aveia foram 18,51, 174,50 e $38,50 \mathrm{mg} \mathrm{kg}^{-1}$, respectivamente. No caso do B e Zn, o maior valor encontrado foi com a aplicação de $8 \mathrm{Mg} \mathrm{ha}^{-1}$ de Lcal.

Ainda de acordo com a Tabela 4, os teores de Mn na parte aérea de aveia preta foram reduzidos em função da aplicação dos resíduos E, LC e Lcal, sendo o mesmo observado em menor escala para o resíduo LB. Tais resultados vão de acordo com Correa (2005). Os resíduos LC, Lcal e E apresentam constituintes neutralizantes em suas composições e, por isso, atuaram na correção da acidez do solo, reduzindo a disponibilidade de $\mathrm{Mn}$, bem como a 
consequente absorção desse micronutriente pelas plantas de aveia preta. Os maiores valores (174,5 $\left.\mathrm{mg} \mathrm{kg}^{-1}\right)$ foram encontrados no tratamento controle, ou seja, sem aplicação de resíduo.

Trata-se de um trabalho em longo prazo, perfazendo um período de nove anos, onde ocorreram cinco aplicações: 2002, 2005, 2007, 2009 e 2011. Dessa maneira os resultados podem variar conforme o ano de cultivo.

Tabela 4. Teores foliares de micronutrientes na cultura da aveia, decorrente da aplicação superficial dos resíduos LB (lodo de biodigestor), LC (lodo centrifugado com adição de cal), Lcal (lama cal), E (escória de aciaria), sob Sistema Semeadura Direta na safra 11/11. Botucatu, SP.

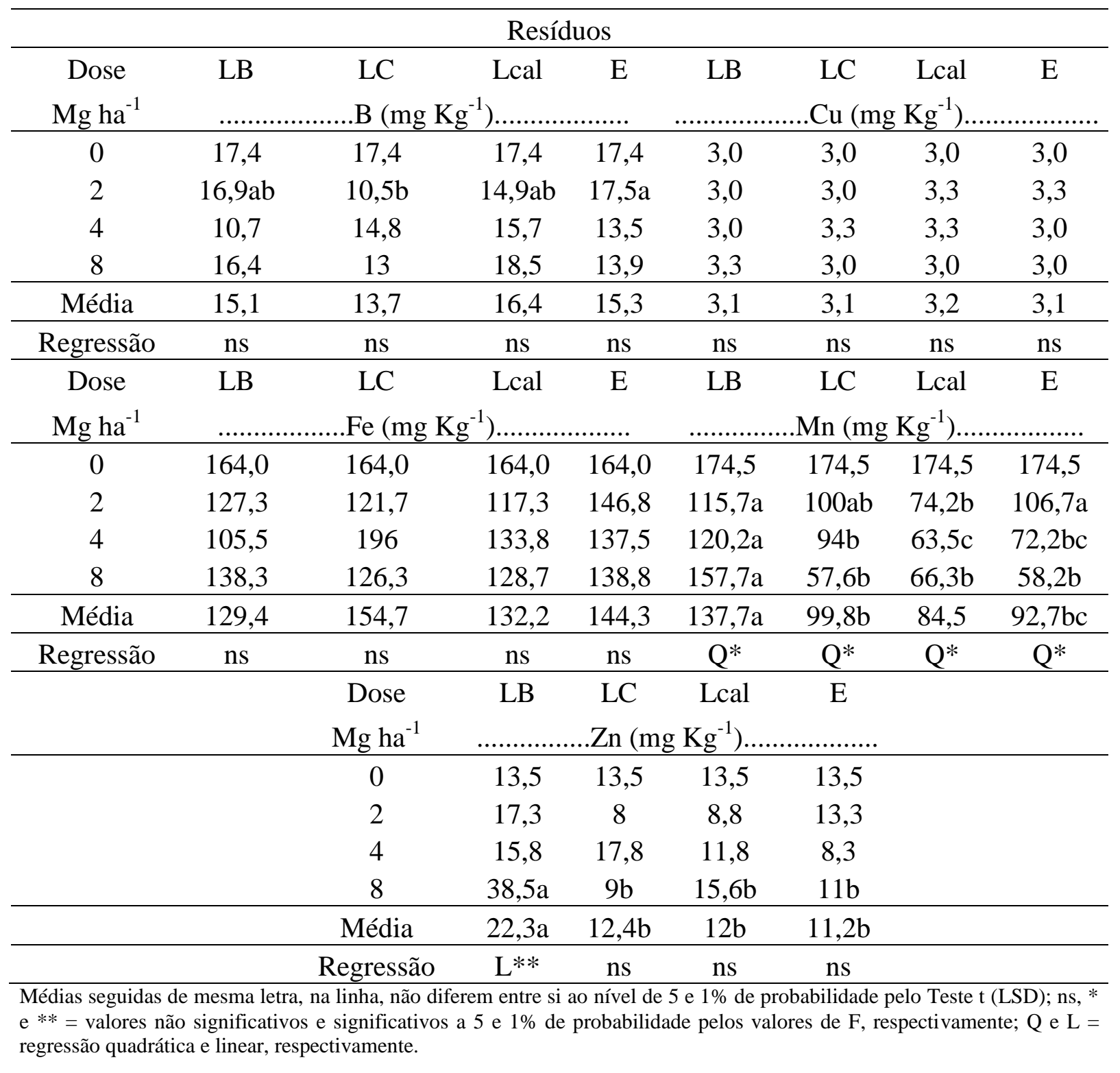

\section{CONCLUSÕES}

1- O resíduo escória foi o que proporcionou os maiores valores de matéria seca da aveia preta.

2- As doses do diferentes resíduos não influenciaram nos valores de N, P, K e S. 
3- Os valores de $\mathrm{B}, \mathrm{Mn}$ e $\mathrm{Zn}$ apresentaram diferença significativa em relação às doses de resíduos.

\section{AGRADECIMENTOS}

Á Capes pela concessão de bolsa a primeira autora durante o curso de doutorado.

\section{REFERÊNCIAS}

ABREU, C. A.; ABREU, M. F.; RAIJ, B.; BATAGLIA, O. C.; ANDRADE, J. C. Extraction of boron from soil by microwave heating for ICP-AES determination. Plant Production Sciense, Japão, v. 1, n. 2, p. 96-103, 1998.

AMADO, T. J. C.; SANTI, A.; ACOSTA, J. A. A. Adubação nitrogenada na aveia preta. II Influência na decomposição de resíduos, liberação de nitrogênio e rendimento de milho sob sistema plantio direto. Revista Brasileira de Ciência do Solo, Viçosa-MG, v. 27, n. 6, 1085 1096, 2003.

BATAGLIA, O. C.; FURLANI, A. M. C.; TEIXEIRA, J. F. P; FURLANI, P. R.; GALLO, J. R. Métodos de análises químicas de plantas. Campinas-SP: Instituto Agronômico, 1983. 48 p. (Boletim Técnico, 78).

BERTON, R. S.; VAlADARES, J. M. A. S.; CAMARGO, O. A.; BATAGLiA, O. C. Peletização de biossólidos e adição de $\mathrm{CaCO}_{3}$ na produção de matéria seca e absorção de $\mathrm{Zn}$, $\mathrm{Cu}$ e Ni pelo milho em três latossolos. Revista Brasileira de Ciência do Solo, Viçosa-MG, v. 21, n. 4, p. 685-691, 1997.

BERTON, R. S.; CAMARGO, O. A.; VALADARES, J. M. A. S. Absorção de nutrientes pelo milho em resposta à adição de lodo de esgoto a cinco solos paulistas. Revista Brasileira de Ciência do Solo, Viçosa-MG, v. 13, n. 1, p. 187-192, 1989.

BORKERT, C. M.; GAUDÊNCIO, C. A.; JUNIOR, A. O.; PEREIRA, J. E.; PEREIRA, L. R. Nutrientes minerais na biomassa da parte aérea em culturas de cobertura de solo. Pesquisa Agropecuária Brasileira, Brasília-DF, v. 38, n. 1, p. 143-153, jan. 2003.

CAMARGO, O. A.; MONIZ, A. C.; JORGE, J. A.; VAlADARES, J. M. A. S. Métodos de análise química, mineralógica e física de solo do Instituto Agronômico de Campinas. Campinas-SP: Instituto Agronômico de Campinas, 1986. 94 p. (Boletim Técnico, 106).

CARVAlHO-PUPATTO, J. G.; BÜLL, L. T.; CRUSCIOL, C. A. C. Atributos químicos do solo, crescimento radicular e produtividade do arroz de acordo com a aplicação de escórias. Pesquisa Agropecuária Brasileira, Brasília-DF, v. 39, n. 12, p. 1213-1218, 2004.

CORRÊA J. C.; BÜLL, L. T.; CRUSCIOL A. C.; TECCHIO M. A. Aplicação superficial de escória, lama cal, lodos de esgoto e calcário na cultura da soja. Pesquisa Agropecuária Brasileira, Brasília-DF, v. 43, n. 9, p. 1209-1219, 2008.

CORRÊA,J. C.; FREITAG, E. E.; BÜLL, L. T.; CRUSCIOL, C. A. C.; FERNANDES, D. M.; Marcelino, R. Aplicação superficial de calcário e diferentes resíduos em soja cultivada no sistema plantio direto. Bragantia, Campinas-SP, v. 68, n. 4, p. 1059-1068, 2009.

EMPRESA BRASILEIRA DE PESQUISA AGROPECUÁRIA. Centro Nacional de Pesquisa de Solos. Sistema brasileiro de classificação de solos. Brasília, DF: EMBRAPA Produção de Informação; Rio de Janeiro-RJ: Embrapa solos, 1999. 412 p. 
GALDO, M. V.; DE MARIA, I. C.; CAMARGO, O. A. Atributos químicos e produção do milho em um Latossolo Vermelho Eutroférrico tratado com lodo de esgoto. Revista Brasileira de Ciência do Solo, Viçosa-MG, v.28, n. 3, p. 569-577, 2004.

LOUZADA, P. T. C. Eficiência de uma escória de siderurgia como corretivo e fertilizante do solo. 1977. 52 p. Dissertação (Mestrado em Solos e Nutrição de Plantas) - Universidade Federal de Viçosa, Viçosa-MG, 1987.

MALAVOLTA, E.; VITTI, G. C.; OLIVEIRA, S. A. Avaliação do estado nutricional de plantas: princípios e aplicações. 2. ed. Piracicaba-SP: Potafós, 1997. 319 p.

MELFI, A. J.; MONTES, C. R. Impacto dos biossólidos sobre o solo. In: TSUTIYA, M. T.; COMPARINI, J. P.; SOBRINHO, P. A.; HESPANHOL, I.; CARVALHO, P. C. T.; MELFI, A. J.; MELO, W. J.; MARQUES, M. O. Biossólidos na Agricultura. São Paulo-SP: SABESP, 2001. 468 p. cap. 9

MELO, W. J.; MARQUES, M. O.; MELO, V. P. O uso agrícola do biossólido e as propriedades do solo. In: TSUTIYA, M. T.; COMPARINI, J. P.; SOBRINHO, P. A.; HESPANHOL, I.; CARVALHO, P. C. T.; MELFI, A. J.; MELO, W. J.; MARQUES, M. O. Biossólidos na agricultura. São Paulo-SP: Companhia de Saneamento Básico do Estado de São Paulo, 2001. p. 289-363.

NASCIMENTO, C. W. A.; BARROS, D. A. S.; MELO, E. E. C.; OLIVEIRA, A. B. Alterações Químicas em solos e crescimento de milho e feijoeiro após aplicação de lodo de esgoto. RevistaBrasileira de Ciência do Solo, Viçosa-MG, v. 21, n. 2, p. 385-392, 2004.

OLIVEIRA, F. C.; MATTIAZZO, M. E.; MARCIANO, C. R.; ROSETTO, R. Efeitos de aplicações sucessivas de lodo de esgoto em um Latossolo Amarelo Distrófico cultivado com cana-de-açúcar: carbono orgânico, condutividade elétrica, pH e CTC. Revista Brasileira de Ciência do Solo, Viçosa-MG, v. 26, n. 2, p. 505-519, 2002.

OLIVEIRA, E. L.; PAVAN, M. A. Control of soil acidity in no-tillage system for soybean production. Soil and Tillage Research, Amsterdam, v. 38, n. 1,2, p. 47-57, 1996.

PEREIRA, J. E. Solubilidade de alguns calcários e escórias de alto forno. 1978. 84 p. Dissertação (Mestrado em Fitotecnia) - Universidade Federal de Viçosa, Viçosa-MG, 1978.

PIAU, W. C. Viabilidade do uso de escórias como corretivo e fertilizantes. 1991. 99 p. Dissertação (Mestrado em Ciências/Energia Nuclear na Agricultura) - Universidade de São Paulo, Piracicaba-SP, 1991.

PRADO, R. M.; NATALE, W.; FERNANDES, F. M.; CORRÊA, M. C. M. Reatividade de uma escória de siderurgia em um Latossolo Vermelho Distrófico. Revista Brasileira de Ciência do Solo, Viçosa-MG, v. 28, n. 1, p. 197-205, 2004.

PRADO, R. M.; FERNANDES, F. M.; NATALE, W. Efeito residual da escória de siderurgia como corretivo de acidez do solo na soqueira de cana-de-açúcar. Revista Brasileira de Ciência do Solo, Viçosa-MG, v. 27, n. 2, p. 287-296, 2003.

PRADO, R. M.; COUTINHO, E. E. M.; ROQUE, C. G.; VILlAR, M. L. P. Avaliação da escória de siderurgia e de calcários como corretivos da acidez do solo no cultivo da alface. Pesquisa agropecuária brasileira, Brasília-DF, v. 37, n. 4, p. 539-546, 2002.

RAIJ, B. V.; CANTARElla, H.; QUAGGIO, J. A.; FURLANI, A. M. C. (Eds). Recomendações de adubação e calagem para o estado de São Paulo. 2. ed. rev. atual. Campinas-SP: Instituto Agronômico de Campinas, 1997. 285 p. (Boletim Técnico, 100). 
RAIJ, B. V.; QUAGGIO, J. A. Métodos de análise de solo para fins de fertilidade. Campinas-SP: Instituto Agronômico de Campinas, 1983. 31 p. (Boletim Técnico, 81).

ROS, C. O.; AITA, C.; CERETTAM, C. A.; FRIES, M. R. Lodo de esgoto: efeito imediato no milheto e residual na associação aveia-ervilhaca. Revista Brasileira de Ciência do Solo, Campinas-SP, v. 17, n. 2, p. 257-261, 1993.

SANTOS, G. A.; CAMARGO, F. A. O. Fundamentos da matéria orgânica no solo: ecossistemas tropicais e subtropicais. Porto Alegre-RS: Gênesis, 1999. 518 p.

TSUTIYA, M. T.; COMPARINI, J. B.; ALEM SOBRINHO, P.; HESPANHOL, I.; CARVAlHO, P. C. T.; MELFI, A. J.; MELO, W. J.; MARQUES, M. O. Biossólidos na agricultura. São Paulo-SP: Sabesp, 2001. 468 p.

VELOSO, C. A. C., BORGES, A. L., MUNIZ, A. S., VEIGAS, J. A. Efeitos de diferentes materiais no pH do solo. Scientia Agrícola, Piracicaba-SP, v. 49, n. 1, p. 123-8, 1992. 